\title{
The Battle against Measles in Pakistan-the Current Scenario
}

ISSN: 2637-7632

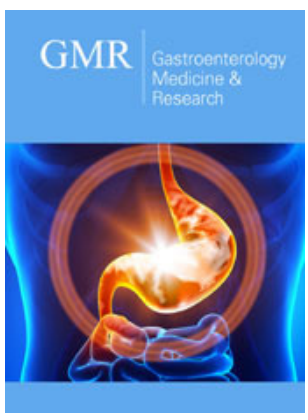

${ }^{* 1}$ Corresponding author: Ishtiaq Qadri, Department of Biological Sciences, Saudi Arabia

Submission: 侮 May 07, 2019

Published: 监May 29, 2019

Volume 3 - Issue 2

How to cite this article: Asif I, Zainab $\mathrm{Y}$, Kaneez F I Q Walla A, Mahd R, et al. The Battle against Measles in Pakistan-the Current Scenario. Gastro Med Res. 3(2). GMR.000556 2019.

DOI: 10.31031/GMR.2019.03.000556

Copyright@ Ishtiaq Qadri,This article is distributed under the terms of the Creative Commons Attribution 4.0 International License, which permits unrestricted use and redistribution provided that the original author and source are credited.

\author{
Asif Islam ${ }^{1}$, Zainab Younas ${ }^{1}$, Kaneez Fatima Ishtiaq Qadri², Walla Alelwani ${ }^{2}$, \\ Mahd Rauf3 and Ishtiaq Qadri** \\ ${ }^{1}$ Department of Medicine, Pakistan \\ ${ }^{2}$ Department of Applied Biochemistry, Faculty of Sciences, Saudi Arabia \\ ${ }^{3}$ Department of Microbiology and Molecular Genetics, Pakistan \\ ${ }^{4}$ Department of Biological Sciences, Saudi Arabia
}

\section{Short Communication}

Measles causes more deaths than any other vaccine preventable disease. In 2016, the ruthless contagion claimed nearly 90,000 lives. In fact, the neglected disease is rebounding in many parts of the world. Several countries reported devastating outbreaks of measles in the past decade: Philippines, Romania, Germany, Italy, Bulgaria, and Vietnam, to name but a few. The story is no different in Pakistan. Pakistan has experienced multiple outbreaks of measles in the last six years. It has been nearly four decades since the establishment of the Expanded Programme on Immunisation (EPI) in Pakistan. Moreover, the country is also a part of the Measles and Rubella Global Strategic Plan (2012-2020), erected by the WHO. Despite that, the coverage against measles and other vaccine preventable diseases is direly poor in Pakistan. According to the Pakistan Demographic Health Surveys and the Pakistan Social and Living Standard Measurement, the current EPI coverage is $65 \%$ and $88 \%$ percent, respectively [1]. Each year, 2 million Pakistani children do not receive the first dose of measles vaccine [2,3]. The coverage of the second dose is further low: $53 \%$ [4].

In 2011, measles smit 4,386 people in Pakistan and claimed 64 lives [3,5]. In 2012, there had been 2,676 laboratory confirmed cases of measles, including 310 deaths [4]. However, the full-fledge outbreak of measles started at the very end of 2012 in Sindh. The infection quickly disseminated to the other provinces of Pakistan. During the ferocious outbreak, 5,969 people were laboratory confirmed with measles and at least 321 succumbed to the exanthema $[4,6]$. This made Pakistan one the highest measles reporting countries in 2013.

According to Reliefweb weekly epidemiological bulletin, there had been as many as 16,000 suspected cases of measles only in the first half of 2013 [7]. Although this large recrudescence was contained by the end of the year, dosens of minor outbreaks were documented in 2014 [8]. Statistics beyond this year remain nebulous, however, the contagion is definitely lingering in the society. According to some sources, such as The Express Tribune and Outbreak News Today, there had been 2,845 cases of measles in 2016 and 6,494 cases in 2017 [9,10]. Hence, the number of measles cases more than doubled in 2017 , as compared to the previous year.

The upsurge of measles in Pakistan could be attributed to several factors. Graft in the healthcare system, which encompasses illicit allocation of funds, derelict attitude of healthcare workers, quackery, fake vaccination campaigns and marketing of expired drugs, played the central role. Another hurdle is the dissatisfactory health infrastructure. The rural areas of Pakistan have been the epicenters of measles outbreaks and health structure in these areas is even poor. There has been a dearth of immunization centers, vaccine storage facilities and, above all, vaccination staff. Negligence of parents and social unrest caused by the war on terror and refugees further added fuel to the fire.

Pakistan has become hub of measles and the contagion can easily spread to the neighboring countries. Therefore, in order to win this battle, national and international 
organizations must join hands. Furthermore, all the towns and villages must have their own measles action plans. Doing so, though challenging, would ensure complete coverage of measles vaccine. The fact that rural and remote areas of Pakistan are affected the most, further necessitates this approach. Finally, launching measles awareness campaigns, would be the best step towards eradication of this scourge (Figure 1).

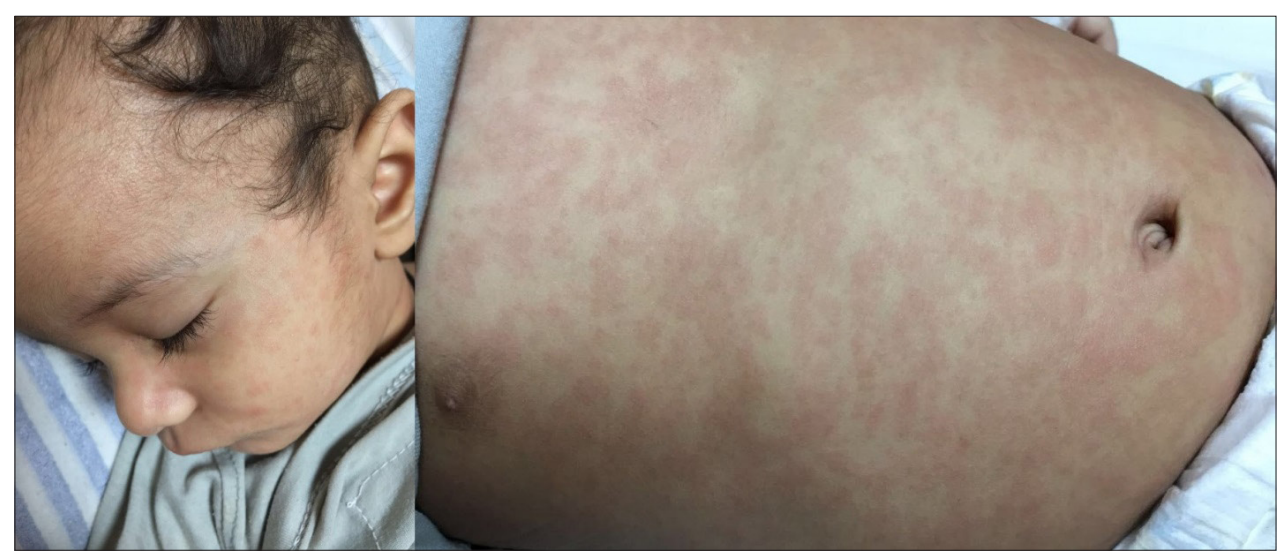

Figure 1: Photographs of a measles patient with maculopapular rash.

\section{References}

1. Keja K, Chan C, Hayden G, Henderson RH (2018) Expanded programme on immunization. World Health Stat Q 41(2): 59-63.

2. Sheikh S, Ali A, Zaidi AK, Agha A, Khowaja A, et al. (2011) Measles susceptibility in children in Karachi, Pakistan. Vaccine 29(18): 34193423.

3. Centers for Disease Control and Prevention (2018) Progress toward regional measles elimination-worldwide, 2000-2017.

4. Khan T, Qazi J (2014) Measles outbreaks in Pakistan: causes of the tragedy and future implications. Epidemiology Reports 2(1): 1.

5. Organization WH (2013) WHO: Measles deaths decline, but elimination progress stalls in some regions.
6. Rehman IU, Bukhsh A, Khan TM (2017) Measles in Pakistan: Time to make steps towards eradication. Travel Med Infect Dis 18: 67-69.

7. Reliefweb (2014) Pakistan: Measles Outbreak-May 2012-Dec 2013.

8. World Health Organization (2014) Reported measles cases and incidence rates by WHO Member States 2013, 2014 as of 11 February 2015.

9. The Express Tribune (2018) Pakistan measles crisis among worst in world.

10. Outbreak News Today (2018) Pakistan sees measles cases more than double in 2017. 